\title{
Encapsulating Sulfur Into Nickel Decorated Hollow Carbon Fibers for High-Performance Lithium-Sulfur Batteries
}

\section{OPEN ACCESS}

Edited by:

Ya You,

Wuhan University of Technology,

China

Reviewed by:

Sen Xin,

Institute of Chemistry (CAS), China

Yuesheng Wang,

Hydro-Québec's Research Institute,

IREQ, Canada

Maowen Xu,

Southwest University, China

*Correspondence:

He Haiyong

hehaiyong@nimte.ac.cn

Zhihong Tang

zhtang@usst.edu.cn

Specialty section:

This article was submitted to Electrochemical Energy Conversion and Storage,

a section of the journal

Frontiers in Energy Research

Received: 15 September 2020

Accepted: 31 December 2020

Published: 24 February 2021

Citation:

Yu D, Tang $Z$ and $H e H$ (2021)

Encapsulating Sulfur Into Nickel Decorated Hollow Carbon Fibers for

High-Performance Lithium-

Sulfur Batteries.

Front. Energy Res. 8:606529. doi: 10.3389/fenrg.2020.606529

\author{
Dongdong $\mathrm{Yu}^{1,2}$, Zhihong Tang ${ }^{1 *}$ and Haiyong $\mathrm{He}^{2 *}$ \\ ${ }^{1}$ School of Materials Science and Engineering, University of Shanghai for Science and Technology, Shanghai, China, ${ }^{2}$ Ningbo \\ Institute of Materials Technology and Engineering, Chinese Academy of Sciences, Ningbo, China
}

Due to the high specific energy density, lithium-sulfur batteries (LSBs) have great potential in energy storage devices for electric vehicle and electronic equipment. However, poor conductivity of sulfur, large volume expansion, and lithium polysulfide dissolution limit LSBs application and promotion. In this work, graphitic hollow carbon fibers (HCF) were fabricated as a matrix to encapsulate sulfur. And nickel particles were introduced into fibers (Ni@HCF) to improve the cycle stability of sulfur cathode. On one hand, hollow structures can encapsulate sulfur and limit lithium polysulfides dissolution, and the graphitic carbon walls can provide a fast electron transport channel. On the other hand, nickel particles can accelerate the conversion of lithium polysulfides. The study results show that the initial discharge specific capacity of $\mathrm{Ni} @ \mathrm{HCF} / \mathrm{S}$ cathodes reaches $1,252 \mathrm{mAh} \mathrm{g}^{-1}$ at the current density of $0.1 \mathrm{C}$. And the capacity can be maintained at $558 \mathrm{mAh} \mathrm{g}^{-1}$ after 200 cycles at the current density of $1 \mathrm{C}$.

Keywords: lithium-sulfur batteries, hollow carbon fibers, graphitic carbon, nickel decoration, lithium polysulfide

\section{INTRODUCTION}

Lithium-sulfur batteries (LSBs), possessing a high energy density of 2,600 Wh kg $\mathrm{Wh}^{-1}$ and merits of low cost and abundance of active materials, have been deemed as the most potential secondary batteries to satisfy the demand for high-density energy storage devices (Chen et al., 2018; Tian et al., 2020). However, there are still some problems impeding the commercial application of LSBs. For instance, the insulating nature of sulfur/lithium sulfide $\left(\mathrm{Li}_{2} \mathrm{~S}\right)$ hinders effective utilization of active materials, tremendous volumetric expansion/shrinkage during sulfur lithiation/delithiation process causes electrode structure deterioration, and active material loss induced by dissolution of lithium polysulfides results in capacity rapid decay (Li et al., 2018; Pang et al., 2018; Wang et al., 2018).

Carbonaceous materials have been proposed and demonstrated as an effective strategy to solve the above problems and enhance the cycling ability of sulfur cathodes. The high electrical conductivity of carbonaceous materials can remedy the insulating nature of sulfur, improving the utilization of active materials. The large volume change during sulfur charge and discharge can be alleviated by the flexible properties of carbonaceous materials. The most prominent advantage of carbonaceous materials may be derived from the employment of porous carbon. The porous structure can encapsulate sulfur and limit the dissolution of lithium polysulfides. Therefore, microporous/mesoporous carbon (Bai et al., 2016; Du et al., 2016; Chen et al., 2017; Jiang et al., 2018), macroporous carbon (Wang et al., 2015; Tang et al., 2017), and carbon nanotubes (CNTs) (Liu et al., 2017b; Luo et al., 2018b; Xin et al., 2012) have been proved with a greatly improved lithium storage performance. Among these porous carbon materials, CNTs exhibit prominent merit in encapsulating sulfur (Jin et al., 2016). The hollow structure can provide a large void 


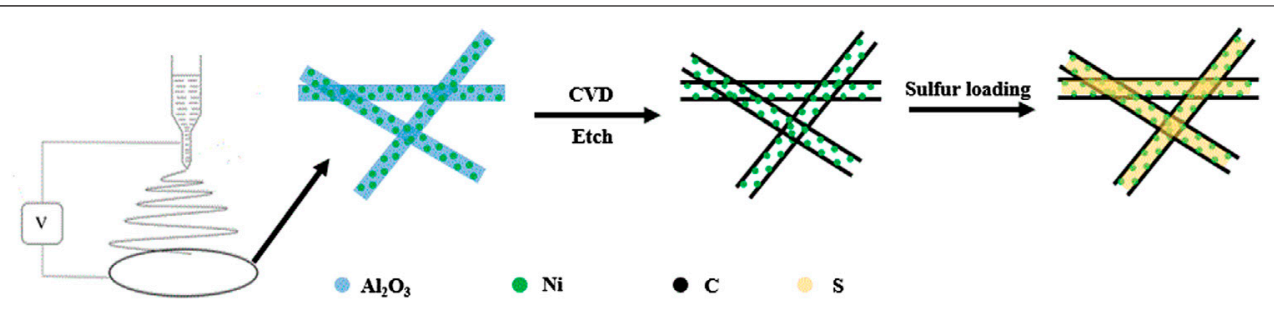

FIGURE 1 | Schematic illustration of the synthesis strategy used to prepare the Ni@HCF/S.
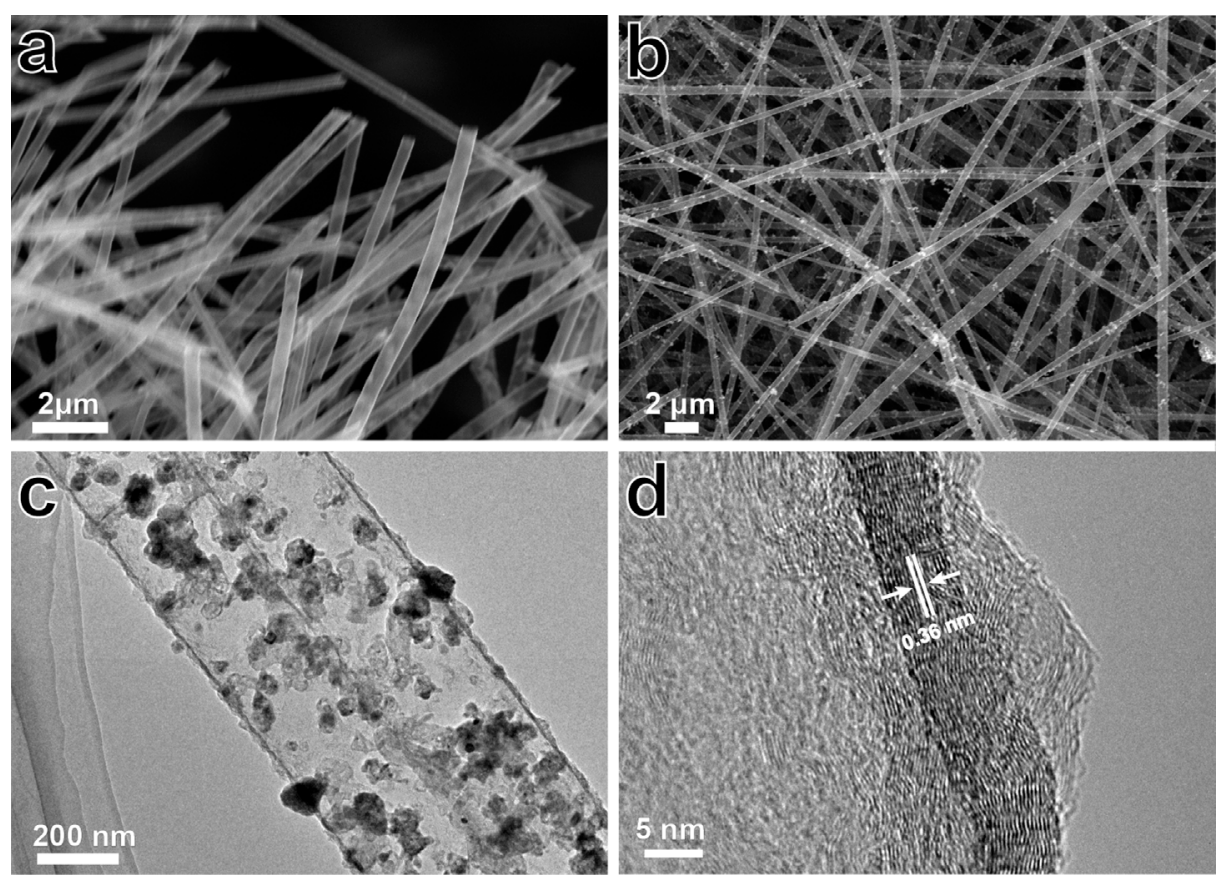

FIGURE 2 | SEM images of HCF (A) and Ni@HCF (B). (C and D) TEM images of Ni@HCF.

space for sulfur loading and restrain lithium polysulfides migration. However, weak affinity toward LiPSs and sluggish redox kinetics still impede sulfur-carbon composite material from achieving high performance (Balach et al., 2018). To meet such a requirement, various polar materials including metals (Zeng et al., 2018; Zhang et al., 2018), metal oxides (Tao et al., 2016; Li et al., 2019), and metal sulfides (Liu et al., 2017a; Zhang et al., 2019) have been developed as lithium polysulfide absorbents and catalysts to enhance the LiPS redox kinetics. Wu et al. decorated multiwalled carbon nanotubes with nickel for sulfur cathode and achieved improved cycling stability and excellent rate capacity (Wu et al., 2017). Therefore, encapsulating sulfur into metal decorated carbon nanotubes is a feasible strategy to achieve high-performance lithium-sulfur batteries.

Here, we prepared graphitic hollow carbon fibers (HCF) with nickel modified by electrospinning and chemical vapor deposition methods. As shown in Figure 1, Ni@ $\mathrm{Al}_{2} \mathrm{O}_{3}$ fibers fabricated by electrospinning were used as a template to deposit graphitic carbon. Then, $\mathrm{Al}_{2} \mathrm{O}_{3}$ components were removed by etching leaving a hollow structure for sulfur loading. The graphitic HCF can compensate for the poor conductivity of sulfur as well as prevent lithium polysulfides dissolution. The nickel particles distributing in fibers can promote lithium polysulfide decomposition and improve the redox kinetics. This particular structure gives rise to the $\mathrm{Ni@HCF/S} \mathrm{cathodes} \mathrm{an} \mathrm{excellent}$ electrochemical performance, which is better than that of $\mathrm{HCF}$ / $\mathrm{S}$ and $\mathrm{C} / \mathrm{S}$ cathodes. The strategy provides a practicable way to fabricate metal decorated HCF that possess great potential application in the electrode structure design.

\section{RESULTS AND DISCUSSION}

Figures 2A,B show the SEM images of HCFs and Ni@HCFs. Both HCFs and Ni@HCFs exhibited three-dimensional network structures consisting of fibers with a diameter of ca. $300 \mathrm{~nm}$. Nickel particles uniformly scattered in the tube of Ni@HCFs. The TEM images were captured to demonstrate the structural details of Ni@HCFs, the hollow structure of fibers can be observed clearly, and the nickel 

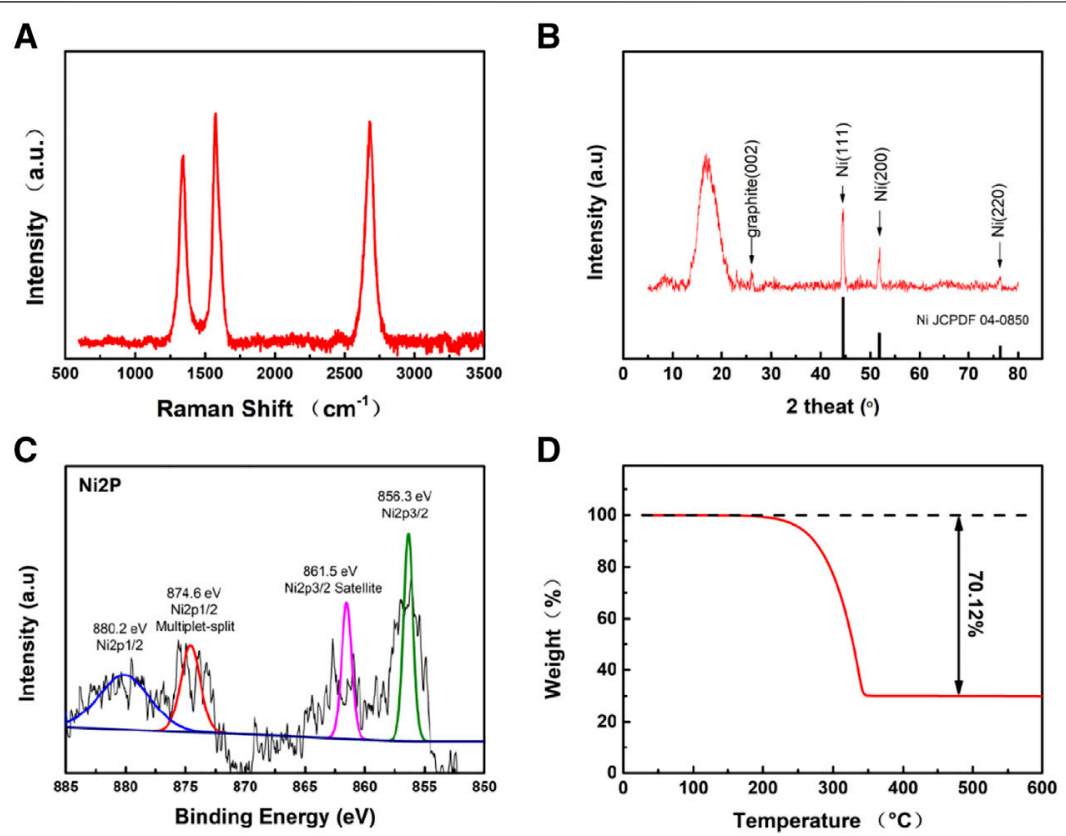

FIGURE 3 | (A) Raman spectra of HCF. (B) XRD spectra of Ni@HCF. (C) Ni 2P XPS spectrum of Ni@HCF. (D) TGA curves of Ni@HCF/S in N2.

particles were distributed uniformly in the tube (Figure 2C). The HRTEM image reveals that the tube walls with a thickness of $15 \mathrm{~nm}$ and lattice spacing of $0.36 \mathrm{~nm}$ (Figure 2D) manifested a highly graphitic carbon of Ni@HCFs. Further, Raman spectrum was adopted to characterize the carbon structure of Ni@HCFs (Figure 3A). Three obvious peaks located at $1,348 \mathrm{~cm}^{-1}$, $1585 \mathrm{~cm}^{-1}$, and $2,694 \mathrm{~cm}^{-1}$ can be observed, corresponding to the $\mathrm{D}$ band, the $\mathrm{G}$ band, and the $2 \mathrm{D}$ band of carbon materials, respectively. The value of $\mathrm{I}_{\mathrm{D}} / \mathrm{I}_{\mathrm{G}}$ ratio of $\mathrm{Ni@HCFs}$ is 0.64 , and $\mathrm{I}_{2 \mathrm{D}} / \mathrm{I}_{\mathrm{D}}$ is 1.21 . The Raman spectrum results indicate the highly ordered carbon of Ni@HCFs (Lee et al., 2018; Luo et al., 2018a). The crystal structure of Ni@HCFs was investigated by X-ray diffraction (XRD) measurements (Figure 3B). The observed diffraction peaks at $44.4,51.7$, and $76.1^{\circ}$ can be attributed to nickel (111), (200), and (220) crystal plane, and the peaks at $26.2^{\circ}$ can be assigned to the graphitic carbon of Ni@HCF. The graphitic carbon walls can enhance the electrical conductivity and improve sulfur utilization. The nickel particles can promote the decomposition of LiPSs and accelerate the redox kinetics. The chemical states of Ni@ HCF were investigated by X-ray photoelectron spectroscopy (XPS). The high-resolution XPS spectrum (Figure 3C) of Ni 2p containing two peaks centered at 854.1 and $862.2 \mathrm{eV}$ is attributed to the $\mathrm{Ni}$ species (Madhu et al., 2015; Zhong et al., 2018). Thermogravimetric Analysis (TGA) was conducted to confirm the sulfur content. As shown in Figure 3D, the sulfur content of Ni@HCF/S was 70.12\%, which was appropriate for the sulfur cathode.

The melt-diffusion method was performed to load sulfur. Figures 3A,B show the SEM and TEM images of Ni@HCF/S composite, respectively. Sulfur was encapsulated in HCF, and no sulfur particle can be observed outside the fibers. The elemental mapping was performed to gain more insight into the component of Ni@HCF/S. As shown in Figures 4C-F, the fibers are composed of $\mathrm{C}, \mathrm{Ni}$, and $\mathrm{S}$ elements, exhibiting homogeneous distribution. Encapsulating sulfur in HCF can suppress the shuttle effect and improve the cycle stability.

Electrochemical performances of $\mathrm{Ni@HCF/S} \mathrm{are} \mathrm{investigated} \mathrm{as}$ cathode materials for LIBs. Figure 5A shows the cyclic voltammetry (CV) curves of the Ni@HCF/S cathode in the voltage window of $1.6-2.8 \mathrm{~V}$ at a scan rate of $0.1 \mathrm{mV} \mathrm{s}^{-1}$. In the first cathodic sweep, two obvious peaks can be observed at 2.22 and $2.02 \mathrm{~V}$, which can be associated with the discharge of $\mathrm{S}_{8}$ forming soluble lithium polysulfides $\left(\mathrm{Li}_{2} \mathrm{~S}_{\mathrm{n}}, 4 \leq n \leq 8\right)$ and further discharge lithium polysulfides generating insoluble $\mathrm{Li}_{2} \mathrm{~S}_{2} / \mathrm{Li}_{2} \mathrm{~S}$ (Manthiram et al., 2014; Seh et al., 2016). In the anodic sweep, a sharp peak located at $2.46 \mathrm{~V}$ can be attributed to oxidization of $\mathrm{Li}_{2} \mathrm{~S}_{2} / \mathrm{Li}_{2} \mathrm{~S}$ (Manthiram et al., 2013; Manthiram et al., 2015). The galvanostatic charge/ discharge curves of Ni@HCF/S and HCF/S cathodes (Figure 5B) manifest two plateaus of conventional LSBs (He et al., 2018; Wang et al., 2020), corresponding to the results of CV curves well. $\mathrm{Ni@HCF/S} \mathrm{cathode} \mathrm{possesses} \mathrm{a} \mathrm{higher} \mathrm{initial} \mathrm{discharge} \mathrm{plateau} \mathrm{and}$ lower charge overpotential, indicating faster kinetics than HCF/S cathode. In the first cycle, the Ni@HCF/S cathode delivers a reversible capacity of $1,252 \mathrm{mAh} \mathrm{g}^{-1}$ at $0.1 \mathrm{C}$, which means a high sulfur utilization of 74.7\%. Figure 5C shows the rate performance of Ni@ $\mathrm{HCF} / \mathrm{S}, \mathrm{HCF} / \mathrm{S}$, and S/C cathodes at $0.1,0.2,0.5,1$, and $2 \mathrm{C}$. All the cathodes possess discharge capacities of more than $1,100 \mathrm{mAh} \mathrm{g}^{-1}$ and then the discharge capacities of $\mathrm{HCF} / \mathrm{S}$ and $\mathrm{S} / \mathrm{C}$ cathodes dropped drastically in the initial five cycles. But Ni@HCF/S cathode capacity declines slowly and stabilizes at $970 \mathrm{mAh} \mathrm{g}^{-1}$ at the fifth cycle. Then Ni@HCF/S cathodes delivered capacities of 844, 723,608 , and $428 \mathrm{mAh} \mathrm{g}^{-1}$ at $0.2,0.5,1$, and $2^{\circ} \mathrm{C}$, much higher than $\mathrm{HCF} / \mathrm{S}$ and S/C cathodes. The Nyquist plots of the Ni@HCF/S, HCF/ $\mathrm{S}$, and $\mathrm{S} / \mathrm{C}$ cathodes were obtained using impedance spectroscopy as shown in Figure 5D. All the curves are composed of a semicircle at 

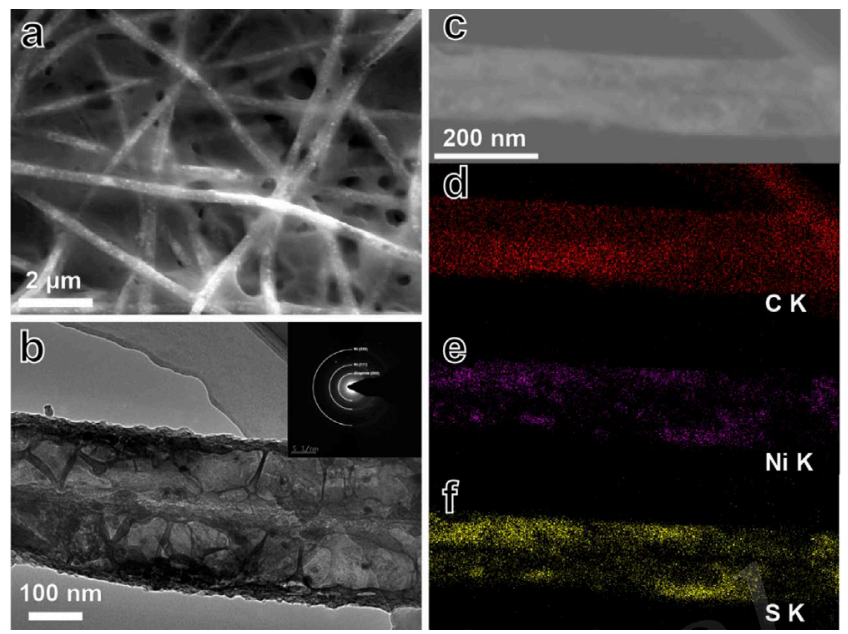

FIGURE 4 | (A) SEM images of Ni@HCF/S. (B) TEM image of Ni@HCF/S. The insert shows the SAED image of Ni@HCF/S. (C) STEM image of Ni@HCF/S and corresponding elemental mapping of $\mathrm{C}(\mathrm{d})$, Ni(e) and $\mathrm{S}(\mathrm{f})$.
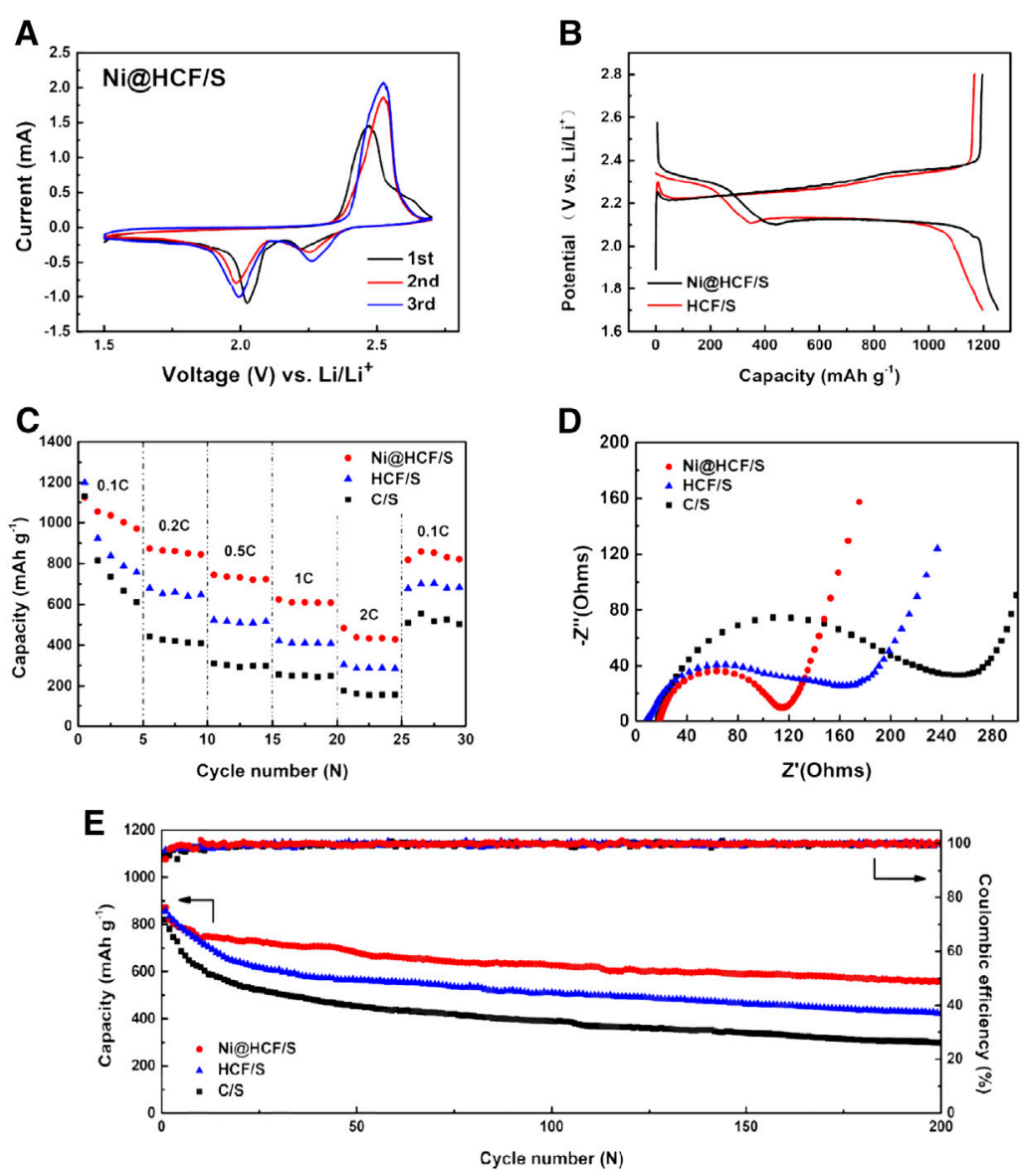

FIGURE 5 | (A) CV curves of the Ni@HCF/S cathode at a scan rate of $0.1 \mathrm{mv} \cdot \mathrm{s}^{-1}$. (B) Galvanostatic charge-discharge profiles of Ni@HCF/S and HCF/S cathodes at a rate of 0.1 C. (C) Rate performance and (D) Nyquist plots of the Ni@HCF/S, HCF/S, and C/S cathodes. (E) Long-term cycling stability of the Ni@HCF/S, HCF/S, and $\mathrm{C} / \mathrm{S}$ cathodes at $1 \mathrm{C}$ for 200 cycles. 
high frequencies associated with the charge transfer resistance $\left(\mathrm{R}_{\mathrm{ct}}\right)$ at the electrode/electrolyte interface and a sloping line at low frequencies related to the Warburg impedance $\left(\mathrm{W}_{0}\right)$ (Su and Manthiram, 2012). The $\mathrm{R}_{\mathrm{ct}}$ value of the Ni@HCF/S cathode was $82.4 \Omega \mathrm{cm}^{-2}$, less than that of HCF/S $\left(127.6 \Omega \mathrm{cm}^{-2}\right)$ and S/C $\left(202.5 \Omega \mathrm{cm}^{-2}\right)$ cathodes, showing that $\mathrm{Ni@HCF/S} \mathrm{cathode} \mathrm{has} \mathrm{a} \mathrm{faster} \mathrm{interface} \mathrm{response} \mathrm{due}$ to the accelerated redox kinetics by nickel particles. As shown in Figure 5E, the cycling performances of $\mathrm{Ni@HCF/S,} \mathrm{HCF/S,} \mathrm{and} \mathrm{S/C}$ cathodes were measured over 200 charging/discharging cycles at $1 \mathrm{C}$. The initial discharge capacity of 857 and $780 \mathrm{mAh} \mathrm{g}^{-1}$ for CNT/S and $\mathrm{S} / \mathrm{C}$ cathodes rapidly dropped to 634 and $540 \mathrm{mAh} \mathrm{g}^{-1}$ at the 20th cycle, respectively. Then, the capacities for $\mathrm{HCF} / \mathrm{S}$ and S/C cathodes steadily decayed down to 423 and $297 \mathrm{mAh} \mathrm{g}^{-1}$, corresponding to 49.3 and $38.1 \%$ of the initial value at the 200 th cycle, respectively. For the Ni@HCF/S cathode, the cycling performance was improved, showing $64.1 \%$ capacity retention from 871 to 558 mAh $\mathrm{g}^{-1}$ over 200 cycles. The improved performance of Ni@ $\mathrm{HCF} / \mathrm{S}$ cathode can be attributed to the encapsulation of sulfur into tubes alleviating the shuttle effect of lithium polysulfides and acceleration of redox kinetics by nickel species.

\section{CONCLUSION}

In summary, nickel decorated graphitic HCF are proved to be a potential structure for sulfur loading in LSBs. The graphitic walls of carbon tube increase the conductivity of composites; meanwhile, tube structure can encapsulate sulfur avoiding lithium polysulfides dissolution. Additionally, the nickel particles can promote the conversion of lithium polysulfides. The prepared Ni@HCF/S cathodes occupied a lower charge transfer resistance and maintained a capacity of $558 \mathrm{mAh} \cdot \mathrm{g}^{-1}$ after 200 cycles at a rate of $1 \mathrm{C}$, showing superior performance than $\mathrm{HCF} / \mathrm{S}$ and $\mathrm{C} / \mathrm{S}$ cathodes.

\section{EXPERIMENTAL SECTION}

\section{Fabrication of Ni@HCF}

Typically, $0.04 \mathrm{~mol}$ aluminum power (Sigma-Aldrich) was added to a $30 \mathrm{ml}$ aqueous solution containing $6.7 \mathrm{ml}$ formic acid (SigmaAldrich) and $7.0 \mathrm{ml}$ acetic acid (Sigma-Aldrich). The mixture was heated to $70^{\circ} \mathrm{C}$ and reacted for $12 \mathrm{~h}$; after cooling down naturally, impurities were removed by filtration. $0.2 \mathrm{~g}$ PEO and $0.4 \mathrm{~g}$ nickel nitrate (Sigma-Aldrich) were dissolved in the obtained solution to form a homogeneous solution for the electrospinning process. $\mathrm{Al}_{2} \mathrm{O}_{3}$ fiber templates were obtained by heating the electrospinning product at $500^{\circ} \mathrm{C}$ for $2 \mathrm{~h}$. Subsequently, the chemical vapor deposition method was performed to grow carbon on the surface of $\mathrm{Al}_{2} \mathrm{O}_{3}$ fiber templates under the temperature of $1,100^{\circ} \mathrm{C}$ and the methane flow of five sccm for 20 min. Finally, the Ni@HCF was obtained by etching the $\mathrm{Al}_{2} \mathrm{O}_{3}$ component with $\mathrm{NaOH}$. The HCF was fabricated by the same route without the addition of nickel nitrate.

\section{Fabrication Composites Cathodes}

The Ni@HCF/S composites were prepared through a melt-diffusion method. Typically, the prepared Ni@HCF and sublimed sulfur were ground together by a mass ratio of 7:3. And the mixture was transferred into an argon-filled autoclave and heated to $155^{\circ} \mathrm{C}$ for 12 h. Then, the slurry containing $80 \mathrm{wt} \%$ active materials, $10 \mathrm{wt} \%$ Super $\mathrm{P}$, and $10 \mathrm{wt} \%$ poly(vinylidene fluoride) binder was cast on $\mathrm{Al}$ foil. At last, the slurry cast Al foil was punched into disks with a diameter of $12 \mathrm{~mm}$. The sulfur loading of the disk was about $1.1 \mathrm{mg}$ $\mathrm{cm}^{-2}$. HCF/S and $\mathrm{C} / \mathrm{S}$ cathodes were fabricated by the same route with $\mathrm{HCF}$ and active carbon, respectively.

\section{Cell Assembly and Test}

CR2032 type coin cells were assembled with carbon-sulfur composite cathodes, single-layer PP separators, and lithium foil as the anode part. $40 \mu \mathrm{L}$ of electrolyte composed of $1 \mathrm{M}$ lithium bis(trifluoromethanesulfonyl)imide (LiTFSI) and $1 \mathrm{wt} \%$ lithium nitrate $\left(\mathrm{LiNO}_{3}\right)$ into 1,3-dioxolane (DOL) and 1,2dimethoxyethane (DME) (volume ratio, 1:1) was added, and the assembly process was performed in an argon-filled glove. Cyclic voltammogram (CV) curves, a voltage window of 1.6-2.8 V, were measured with a potentiostat/galvanostat $1470 \mathrm{E}$ from Solartron at a scan rate of $0.1 \mathrm{mV} \mathrm{S}^{-1}$. The galvanostatic charge-discharge cycling test was performed with a LAND battery test system. Electrochemical impedance spectroscopy (EIS) measurements were carried out using a frequency response analyzer 1455A from Solartron. The impedance spectra were recorded on cells in variable frequency form $10^{6}$ $\mathrm{Hz}$ and $0.1 \mathrm{~Hz}$ with an amplitude of $10 \mathrm{mV}$.

\section{Material Characterizations}

Bruker D8 advanced diffractometer with $\mathrm{Cu} \mathrm{Ka}(\lambda=1.5406 \AA)$ radiation (Bruker AXS, D8 Advance) was used to identify the crystalline phase of the prepared samples. SEM (FEI, QUANTA 250 FEG) and TEM (FEI, Tecnai F20) were employed to analyze the surface morphology and interior structure. Renishaw inVia reflex Raman spectrometer with an excitation wavelength of $532 \mathrm{~nm}$ was adopted to collect Raman spectra of the prepared samples.

\section{DATA AVAILABILITY STATEMENT}

The original contributions presented in the study are included in the article/Supplementary Material; further inquiries can be directed to the corresponding author.

\section{AUTHOR CONTRIBUTIONS}

DY carried out the experiment and wrote the manuscript with support from $\mathrm{HH}$ and $\mathrm{ZT}$. All authors discussed the results and contributed to the final manuscript.

\section{FUNDING}

This work was financially sponsored by the Basic Research Program of Shanghai (19JC1410402), the Scientific Research and Innovation Program of Shanghai Education Commission 
(2019-01-07-00-07-E00015), the Hundred Talents Program, the National Natural Science Foundation of China (Grant No.

\section{REFERENCES}

Bai, S. Y., Liu, X. Z., Zhu, K., Wu, S. C., and Zhou, H. S. (2016). Metal-organic framework-based separator for lithium-sulfur batteries. Nature Energy 1, 6. doi:10.1038/nenergy.2016.94

Balach, J., Linnemann, J., Jaumann, T., and Giebeler, L. (2018). Metal-based nanostructured materials for advanced lithium-sulfur batteries. J. Mater. Chem. 6, 23127-23168. doi:10.1039/c8ta07220e

Chen, K., Sun, Z. H., Fang, R. P., Li, F., and Cheng, H. M. (2018). Development of graphene-based materials for lithium-sulfur batteries. Acta Phys. Chim. Sin. 34, 377-390. doi:10.3866/PKU.WHXB201709001

Chen, Z.-H., Du, X.-L., He, J.-B., Li, F., Wang, Y., Li, Y.-L., et al. (2017). Porous coconut shell carbon offering high retention and deep lithiation of sulfur for lithium-sulfur batteries. ACS Appl. Mater. Interfaces 9, 33855-33862. doi:10. 1021/acsami.7b09310

Du, X-L., You, Y., Yan, Y., Zhang, D., Cong, H-P., Qin, H., et al. (2016). Conductive carbon network inside a sulfur-impregnated carbon sponge: a bioinspired highperformance cathode for li-s battery. ACS Appl. Mater. Interfaces 8, 22261-22269. doi:10.1021/acsami.6b07607

He, B., Li, W.-C., Zhang, Y., Yu, X.-F., Zhang, B., Li, F., et al. (2018). Paragenesis bn/ cnts hybrid as a monoclinic sulfur host for high rate and ultra-long life lithiumsulfur battery. J. Mater. Chem. 6, 24194-24200. doi:10.1039/c8ta09564g

Jiang, H. Q., Liu, X. C., Wu, Y. S., Shu, Y. F., Gong, X., Ke, F. S., et al. (2018). Metalorganic frameworks for high charge-discharge rates in lithium-sulfur batteries. Angew Chem. Int. Ed. Engl. 57, 3916-3921. doi:10.1002/anie.201712872

Jin, F., Xiao, S., Lu, L., and Wang, Y. (2016). Efficient activation of high-loading sulfur by small cnts confined inside a large cnt for high-capacity and high-rate lithium-sulfur batteries. Nano Lett. 16, 440-447. doi:10.1021/acs.nanolett. 5b04105

Lee, B.-J., Park, H.-Y., Yang, D.-S., Kang, T.-H., Hwang, S., and Yu, J.-S. (2018). Mesopore channel length control in ordered mesoporous carbon hosts for high performance lithium-sulfur batteries. J. Electrochem. Soc. 166, A5244-A5251. doi:10.1149/2.0391903jes

Li, G. R., Lei, W., Luo, D., Deng, Y. P., Deng, Z. P., Wang, D. L., et al. (2018). Stringed "tube on cube" nanohybrids as compact cathode matrix for highloading and lean-electrolyte lithium-sulfur batteries. Energy Environ. Sci. 11, 2372-2381. doi:10.1039/c8ee01377b

Li, Y. F., Shi, Y. H., Wang, S. G., Liu, J. H., Lin, J., Xia, Y., et al. (2019). Carbon/ binder-free nio@nio/nf with in situ formed interlayer for high-areal-capacity lithium storage. Adv. Energy Mater. 9, 9. doi:10.1002/aenm.201803690

Liu, X., Huang, J. Q., Zhang, Q., and Mai, L. Q. (2017a). Nanostructured metal oxides and sulfides for lithium-sulfur batteries. Adv Mater Weinheim 29, 25. doi:10.1002/adma.201601759

Liu, Y. Z., Li, G. R., Fu, J., Chen, Z. W., and Peng, X. S. (2017b). Strings of porous carbon polyhedrons as self-standing cathode host for high-energy-density lithium-sulfur batteries. Angew Chem. Int. Ed. Engl. 56, 6176-6180. doi:10. 1002/anie. 201700686

Luo, S., Sun, W., Ke, J., Wang, Y., Liu, S., Hong, X., et al. (2018a). A 3d conductive network of porous carbon nanoparticles interconnected with carbon nanotubes as the sulfur host for long cycle life lithium-sulfur batteries. Nanoscale 10, 22601-22611. doi:10.1039/c8nr06109b

Luo, L. Y., Qin, X. Y., Wu, J. X., Liang, G. M., Li, Q., Liu, M., et al. (2018b). An interwoven moo3@cnt scaffold interlayer for high-performance lithium-sulfur batteries. J. Mater. Chem. 6, 8612-8619. doi:10.1039/c8ta01726c

Madhu, R., Veeramani, V., Chen, S-M., Veerakumar, P., and Liu, S-B. (2015). Functional porous carbon/nickel oxide nanocomposites as binder-free electrodes for supercapacitors. Chemistry 21, 8200-8206. doi:10.1002/chem.201500247

Manthiram, A., Chung, S-H., and Zu, C. (2015). Lithium-sulfur batteries: progress and prospects. Adv Mater Weinheim 27, 1980-2006. doi:10.1002/adma. 201405115

Manthiram, A., Fu, Y., Chung, S-H., Zu, C., and Su, Y-S. (2014). Rechargeable lithium-sulfur batteries. Chem. Rev. 114, 11751-11787. doi:10.1021/cr500062v
51872304), and the Ningbo S\&T Innovation 2025 Major Special Program (2018B10024).
Manthiram, A., Fu, Y., and Su, Y-S. (2013). Challenges and prospects of lithiumsulfur batteries. Acc. Chem. Res. 46, 1125-1134. doi:10.1021/ar300179v

Pang, Q., Shyamsunder, A., Narayanan, B., Kwok, C. Y., Curtiss, L. A., and Nazar, L. F. (2018). Tuning the electrolyte network structure to invoke quasi-solid state sulfur conversion and suppress lithium dendrite formation in li-s batteries. Nat Energy 3, 783-791. doi:10.1038/s41560-018-0214-0

Seh, Z. W., Sun, Y., Zhang, Q., and Cui, Y. (2016). Designing high-energy lithiumsulfur batteries. Chem. Soc. Rev. 45, 5605-5634. doi:10.1039/c5cs00410a

Su, Y-S., and Manthiram, A. (2012). Lithium-sulphur batteries with a microporous carbon paper as a bifunctional interlayer. Nat. Commun. 3, 1166. doi:10.1038/ ncomms 2163

Tang, Q. O., Li, H. Q., Zuo, M., Zhang, J., Huang, Y. Q., Bai, P. W., et al. (2017). Optimized assembly of micro-/meso-/macroporous carbon for li-s batteries. Nano 12, 9. doi:10.1142/s1793292017500217

Tao, X. Y., Wang, J. G., Liu, C., Wang, H. T., Yao, H. B., Zheng, G. Y., et al. (2016). Balancing surface adsorption and diffusion of lithium-polysulfides on nonconductive oxides for lithium-sulfur battery design. Nat. Commun. 7, 11203. doi:10.1038/ncomms11203

Tian, Y., Li, G. R., Zhang, Y. G., Luo, D., Wang, X., Zhao, Y., et al. (2020). Lowbandgap se-deficient antimony selenide as a multifunctional polysulfide barrier toward high-performance lithium-sulfur batteries. Adv. Mater. 32, 11. doi:10. 1002/adma.202070030

Wang, C., Wang, X. S., Wang, Y. J., Chen, J. T., Zhou, H. H., and Huang, Y. H. (2015). Macroporous free-standing nano-sulfur/reduced graphene oxide paper as stable cathode for lithium-sulfur battery. Nano Energy 11, 678-686. doi:10. 1016/j.nanoen.2014.11.060

Wang, W-P., Zhang, J., Yin, Y-X., Duan, H., Chou, J., Li, S-Y., et al. (2020). A rational reconfiguration of electrolyte for high-energy and long-life lithiumchalcogen batteries. Adv. Mater. 32, e2000302. doi:10.1002/adma.202000302

Wang, Y. Z., Huang, X. X., Zhang, S. Q., and Hou, Y. L. (2018). Sulfur hosts against the shuttle effect. Small Methods 2, 1700345. doi:10.1002/smtd.201700345

Wu, X., Yao, S., Hou, J., Jing, M., Qian, X., Shen, X., et al. (2017). Effect of nickel coated multi-walled carbon nanotubes on electrochemical performance of lithium-sulfur rechargeable batteries. J. Nanosci. Nanotechnol. 17, 2482-2487. doi:10.1166/jnn.2017.13907

Xin, S., Gu, L., Zhao, N-H., Yin, Y-X., Zhou, L-J., Guo, Y-G., et al. (2012). Smaller sulfur molecules promise better lithium-sulfur batteries. J. Am. Chem. Soc. 134, 18510-18513. doi: $10.1021 / \mathrm{ja} 308170 \mathrm{k}$

Zeng, W., Wang, Z., Cheng, M. M.-C., and Ng, K. Y. S. (2018). Structured titanium nitride nanotube arrays/sulfur composite as cathode materials for advanced lithium sulfur battery. J. Electrochem. Soc. 165, A1011-A1018. doi:10.1149/2. 0851805jes

Zhang, H., Lin, C., Hu, X., Zhu, B., and Yu, D. (2018). Effective dual polysulfide rejection by a tannic acid/FeIII complex-coated separator in lithium-sulfur batteries. ACS Appl. Mater. Interfaces 10, 12708-12715. doi:10.1021/acsami.8b01189

Zhang, K. L., Chen, F. F., Pan, H. L., Wang, L., Wang, D., Jiang, Y., et al. (2019). Study on the effect of transition metal sulfide in lithium-sulfur battery. Inorg. Chem. Front. 6, 477-481. doi:10.1039/c8qi01193a

Zhong, Y., Xia, X., Deng, S., Zhan, J., Fang, R., Xia, Y., et al. (2018). Popcorn inspired porous macrocellular carbon: rapid puffing fabrication from rice and its applications in lithium-sulfur batteries. Adv. Energy Mater. 8, 1701110. doi:10.1002/aenm.201701110

Conflict of Interest: The authors declare that the research was conducted in the absence of any commercial or financial relationships that could be construed as a potential conflict of interest.

Copyright (c) $2021 \mathrm{Yu}$, Tang and He. This is an open-access article distributed under the terms of the Creative Commons Attribution License (CC BY). The use, distribution or reproduction in other forums is permitted, provided the original author(s) and the copyright owner(s) are credited and that the original publication in this journal is cited, in accordance with accepted academic practice. No use, distribution or reproduction is permitted which does not comply with these terms. 